\title{
Level of physical activity of students in Poland, Portugal and Belarus
}

\author{
Mariola Król ${ }^{1, A-F} \oplus$, Robert Latosiewicz ${ }^{1, A-F} \oplus$, Rui Miguel Marques Brás ${ }^{2, A-F}$, \\ Władisław Barkow ${ }^{3, A-F} \oplus$, Jolanta Grażyna Zuzda ${ }^{4, A-F} \oplus$ \\ ${ }^{1}$ Medical University, Lublin, Poland \\ 2 Universidade de Beira Interior, Covilhã, Portugal \\ ${ }^{3}$ Yanka Kupala State University, Grodno, Belarus \\ ${ }^{4}$ University of Technology, Białystok, Poland \\ A - Research concept and design, B - Collection and/or assembly of data, C - Data analysis and interpretation, \\ $D$ - Writing the article, E - Critical revision of the article, F - Final approval of the article
}

\begin{abstract}
Król M, Latosiewicz R, Marques Brás RM, Barkow W, Zuzda JG. Level of physical activity of the students in Poland, Portugal and Belarus. Ann
\end{abstract} Agric Environ Med. 2022; 29(1): 126-135. doi: 10.26444/aaem/142295

\section{Abstract}

Introduction and objective. The WHO term 'physical activity' refers to all body movements produced by skeletal muscles which require energy expenditure. The ways to be active include daily activities, exertion in the performance of work, or active recreation. The objective of the study is to compare physical activity of the students of Bialystok University of Technology, Higher School of Physical Education and Tourism in Biaystok (Poland), University of Beira Interior in Covilha (Portugal) and Janka Kupala Grodno State University in Grodno (Belarus).

Materials and method. A total of 1,136 persons participated in the study (398 men and 738 women). The level of physical activity of the students was assessed on the basis of a short version of the International Physical Activity Questionnaire (IPAQ). The individual value of the body mass index (BMI) was calculated for each respondent.

Results. Among men studying at WSWFiTB, in Portugal and Belarus, the dominant level of activity was high. Both in the group of men and women, people studying in Portugal spent the most time sitting during one working day. Without taking into account the gender of the respondents, a high level was the dominant among students of WSWFiTB, in Portugal and Belarus. With regard to overweight and obese people, the highest average amount of energy expenditure was recorded in the case of intensive activity.

Conclusions. Men, compared to women, were characterized by a higher average amount of energy consumption related to total activity and intensive exercise. Students in Belarus obtained the highest average amount of energy expenditure related to moderate and intensive activity, compared to students at BUT, WSWFiTB and in Portugal. A high level of activity dominated both in the group of underweight/normal body weight, as well as overweight and obese persons.

Key words

exercise, Body Mass Index, students, physical fitness, energy metabolism

\section{INTRODUCTION}

The WHO term 'physical activity' refers to all body movements produced by skeletal muscles which require energy expenditure. Ways to be active include daily activities, exertion in the performance of work, or active recreation [1].

According to the WHO guidelines, adults should undertake aerobic physical activity of moderate intensity for at least 150-300 minutes per week, or of high intensity for a minimum of 15-150 minutes. The recommended form of activity is also a combination of moderate and intensive activity. Aerobic exercises should be supplemented with strengthening exercises of high or moderate intensity, performed on at least two days a week and involving the main muscle groups [2].

Regular exercise of moderate intensity (i.e. cycling, walking) has a positive impact on the body: it reduces the risk of chronic diseases, including cardiovascular diseases, diabetes, obesity and osteoporosis $[1,3,4,5,6]$.

Address for correspondence: Mariola Król, Medical University, Lublin, Poland E-mail: mariola125-92@o2.pl

Received: 13.08.2020; accepted: 15.09.2021; first published: 29.09.2021

\section{OBJECTIVE}

The aim of the study is to compare the physical activity of students at the University of Technology, Higher School of Physical Education and Tourism in Bialystok (Poland), University of Beira Interior in Covilha (Portugal) and Janka Kupala State University in Grodno (Belarus).

\section{MATERIALS AND METHOD}

A total of 1,136 persons participated in the study: 398 men and 738 women, of whom 456 were Polish - 182 persons studying at the Bialystok University of Technology (group: PL-PB), 265 persons studying at the Higher School of Physical Education and Tourism in Bialystok (group: PL-WSWFiTB), 437 were studying at the University of Beira Interior in Covilha, Portugal (group PT), and 252 participants were studying at the Janka Kupala State University in Grodno in Belarus (group BY). The average age of the respondents was $20.19 \pm 2.26$ years (Tab. 1 ).

The characteristics of the respondent group with regard to gender are shown in Table 2. The highest average results of BMI (Body Mass Index $-\mathrm{kg} / \mathrm{m}^{2}$ ) were recorded among 
Table 1. Characteristics of respondent group (the average \pm standard deviation; $n=1136$ )

\begin{tabular}{|c|c|c|c|c|c|}
\hline Characteristics & Global & $\mathrm{PL}(\mathrm{PB})$ & PL (WSWFiTB) & PT & BY \\
\hline Age (y) & $20.19 \pm 2.26$ & $20.79 \pm 0.68$ & $21.06 \pm 1.01$ & $20.03 \pm 2.70$ & $19.12 \pm 2.62$ \\
\hline Body mass $(\mathrm{kg})$ & $65.82 \pm 12.52$ & $65.79 \pm 12.25$ & $68.20 \pm 13.14$ & $64.46 \pm 12.03$ & $65.70 \pm 12.60$ \\
\hline Height $(\mathrm{cm})$ & $171.50 \pm 9.05$ & $171.79 \pm 8.02$ & $174.36 \pm 8.43$ & $168.66 \pm 8.82$ & $173.23 \pm 9.38$ \\
\hline BMI $\left(\mathrm{kg} / \mathrm{m}^{2}\right)$ & $22.24 \pm 2.98$ & $22.21 \pm 3.42$ & $22.25 \pm 2.70$ & $22.54 \pm 2.96$ & $21.75 \pm 2.90$ \\
\hline
\end{tabular}

Table 2. Characteristics of respondent group with regard to gender (average \pm standard deviation; $n=1136$ )

\begin{tabular}{|c|c|c|c|c|}
\hline \multicolumn{5}{|l|}{ Men } \\
\hline Characteristics & $\mathrm{PL}(\mathrm{PB})$ & PL (WSWFiTB) & PT & BY \\
\hline Sample size & 59 & 131 & 113 & 95 \\
\hline Age (y) & $20.78 \pm 0.70$ & $21.05 \pm 0.74$ & $20.79 \pm 3.75$ & $19.43 \pm 3.95$ \\
\hline Body mass $(\mathrm{kg})$ & $74.53 \pm 9.95$ & $77.55 \pm 10.77$ & $77.02 \pm 12.21$ & $77.15 \pm 8.86$ \\
\hline Height (cm) & $178.87 \pm 6.02$ & $180.27 \pm 6.33$ & $178.63 \pm 7.57$ & $180.55 \pm 7.70$ \\
\hline BMI $\left(\mathrm{kg} / \mathrm{m}^{2}\right)$ & $23.24 \pm 2.44$ & $23.80 \pm 2.58$ & $24.12 \pm 3.40$ & $23.66 \pm 2.31$ \\
\hline Characteristics & $\mathrm{PL}(\mathrm{PB})$ & PL (WSWFiTB) & PT & BY \\
\hline Sample size & 123 & 134 & 324 & 157 \\
\hline Age (y) & $20.79 \pm 0.68$ & $21.07 \pm 1.22$ & $19.77 \pm 2.17$ & $18.93 \pm 1.25$ \\
\hline Body mass $(\mathrm{kg})$ & $61.60 \pm 10.99$ & $59.06 \pm 7.68$ & $60.08 \pm 8.33$ & $58.77 \pm 8.95$ \\
\hline Height (cm) & $168.39 \pm 6.51$ & $168.58 \pm 5.81$ & $165.18 \pm 6.19$ & $168.81 \pm 7.31$ \\
\hline BMI $\left(\mathrm{kg} / \mathrm{m}^{2}\right)$ & $21.71 \pm 3.70$ & $20.72 \pm 1.80$ & $21.99 \pm 2.58$ & $20.58 \pm 2.59$ \\
\hline
\end{tabular}

men studying in Portugal $-24.12 \pm 3.40 \mathrm{~kg} / \mathrm{m}^{2}$, and among students in Belarus - $23.66 \pm 2.31 \mathrm{~kg} / \mathrm{m}^{2}$. Women were characterized by a lower average BMI value compared to men studying at the same universities. The lowest average BMI result was recorded in the group of women in Belarus $-20.58 \pm 2.59 \mathrm{~kg} / \mathrm{m}^{2}$

A diagnostic survey method was used in this study by applying the questionnaire technique. The short version of the International Physical Activity Questionnaire (IPAQ) and the test record were used.

The level of physical activity of the students was assessed on the basis of a short version of the International Physical Activity Questionnaire (IPAQ), which includes 7 questions related to physical activities in everyday life, at work and leisure. The questions in the questionnaire are aimed at gathering information about the time spent by the respondents on performing activities related to walking and sitting, as well as moderate and vigorous efforts. Activities to be taken into account had to last at least 10 continuous minutes [7].

The unit of measurement used to evaluate each form of activity was the MET (Metabolic Equivalent of Task) intensity coefficient, a parameter that determines oxygen uptake based on the multiples of resting metabolic rate. One MET corresponds to $3.5 \mathrm{ml}$ of oxygen per kilogram of body weight in one minute $[8,9,10,11]$. The value of the MET coefficient in relation to the short version of the questionnaire is: 8.0 - for intensive exercise, 4.0 - for moderate exercise, and 3.0 - for exercise related to walking. By multiplying the value of the coefficient assigned to a specific activity by the number of days of this exercise and the duration (min) per day, the specific physical effort can be presented in METmin/week units. After summing-up the results obtained for individual types of activity, weekly physical activity is obtained [7]. The obtained results allow classification of the respondents according to their level of physical activity. Three levels of activity were distinguished: high, sufficient and insufficient. People with a high level performed vigorous physical activity for 3 or more days (minimum 1,500 MET- $\mathrm{min}$ /week) or for 7 days or more performed as a combination of vigorous, moderate, or walking exercises in excess of 3,000 MET-min/week. A sufficient level was assigned to those who performed intensive activity for at least 20 minutes during the day for at least 3 days, or who performed moderate activity or walking for more than 30 minutes for at least 5 days, or who performed for a minimum of 5 days a combination of physical activities: vigorous, moderate or walking of at least $600 \mathrm{MET}-\mathrm{min} /$ week. On the other hand, an insufficient levelwais characterized by people who did not perform any physical activity, or did not meet the criteria for a high and sufficient level $[7,12,13,14]$.

On the basis of the height and weight values given in the questionnaire, an individual body mass index (BMI) was calculated for each respondent.

In order to interpret the results, the WHO classification was adopted according to whichae BMI value below $18.5 \mathrm{~kg} / \mathrm{m}^{2}$ means underweight, $18.5-24.9 \mathrm{~kg} / \mathrm{m}^{2}$ - normal body weight, $25-29.9 \mathrm{~kg} / \mathrm{m}^{2}$ - overweight, while a value equal to or exceeding $30 \mathrm{~kg} / \mathrm{m}^{2}$ - obesity $[15,16]$.

The obtained results were analyzed statistically. The value of measurable parameters was presented with the mean value, standard deviation, interquartile range, and for nonmeasurable parameters - with the count and percentage. A significance level of $\mathrm{p}<0.05$ was adopted, indicating the existence of statistically significant differences or relationships. Significance values for many of the tests were corrected by the Bonferroni method.

\section{RESULTS}

Among the men studying at WSWFiTB, in Portugal and Belarus, the dominant level of activity was high, 71\%, 53.1\% and $65.3 \%$ of the respondents, respectively. In the group of men with $\mathrm{PB}$, moderate (sufficient) activity was predominant $-40.7 \%$ of the respondents. $28.8 \%$ of men studying at BUT, $3.8 \%$ of men studying at WSWFiTB, $18.6 \%$ of students in 
Portugal, and $7.4 \%$ of students in Belarus were characterized by an insufficient level of activity (Fig. 1).

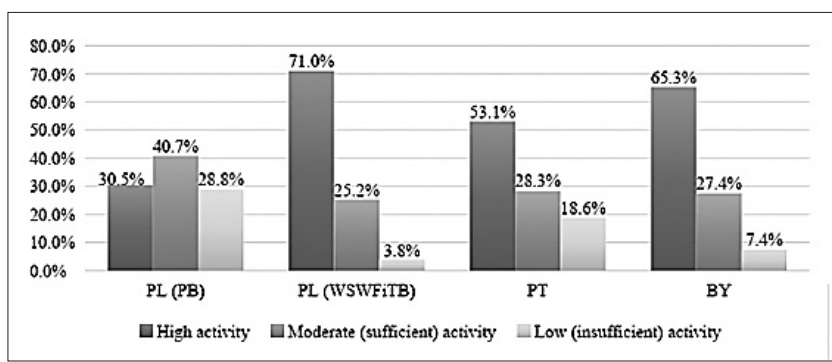

Figure 1. Level of physical activity of men studying at PB, WSWFiTB in Portugal and Belarus

The dominant level of activity among female students of BUT and in Portugal was moderate (sufficient) activity - $53.7 \%$ and $41 \%$ of the respondents, while among women studying at WSWFiTB and in Belarus, the level was high $70.9 \%$ and $60.5 \%$ of the respondents). An insufficient level of activity was found in 36\% of BUT female students, $9 \%$ of women studying at WSWFiTB, 20.1\% of Portuguese female students and $8.9 \%$ of Belarusian students (Fig. 2).

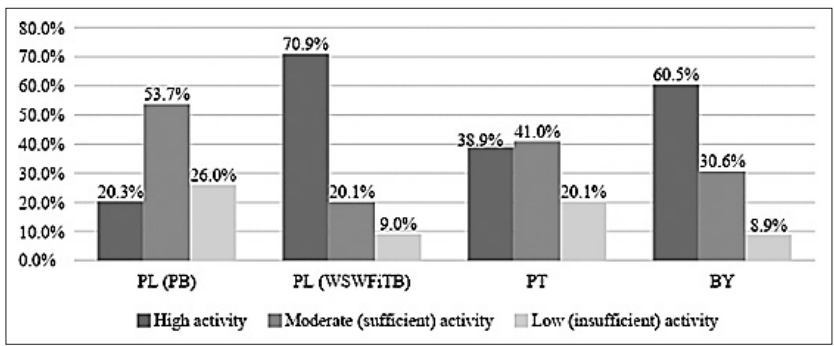

Figure 2. Level of physical activity of women studying at PB, WSWFiTB in Portugal and Belarus

Table 3 shows the time spent by respondents regarding individual physical activity. Taking into account the activity related to walking, the highest average result was recorded among men studying in Belarus and women studying at WSWFiTB - 360 minutes and 350 minute, respectively. The lowest mean value of the same activity was observed in the men and women of $\mathrm{PB}-140$ minutes and 210 minutes, respectively.
Among men, Belarusian students spent the most time on moderate physical activity, and the least time among Portuguese students - 180 minutes and 90 minutes, respectively. When analyzing the average time spent by men on intensive activity, the highest average result was recorded among students in Belarus and Portugal, and the lowest among students of BUT - 240 minutes, 240 minutes and 45 minutes, respectively. Both in relation to moderate and vigorous physical activity, the highest average value of time spent on the above-mentioned activity was recorded among female students of WSWFiTB - 135 minutes and 180 minutes, respectively. The female students in Portugal spent the least amount of time performing moderate exercises, and with regard to intensive exercises, female students of BUT - 60 min and $45 \mathrm{~min}$.

Both in the group of men and women, those studying in Portugal spent the most time sitting during one working day, and the least students in Belarus - 420 minutes and 465 minutes, and 130 minutes and 120 minutes, respectively.

Without taking into account the gender of the respondents, a high level was the dominant level among students of WSWFiTB in Portugal and Belaru $-70.9 \%, 42.6 \%$ and $62.3 \%$, respectively (Fig. 3). With regard to BUT students, moderate (sufficient) activity prevailed $-49.5 \%$ of the respondents. An insufficient level of activity was recorded among $26.9 \%$ of BUT students, $6.4 \%$ of WSWFiTB students, $19.7 \%$ of respondents studying in Portugal and $8.3 \%$ in Belarus.

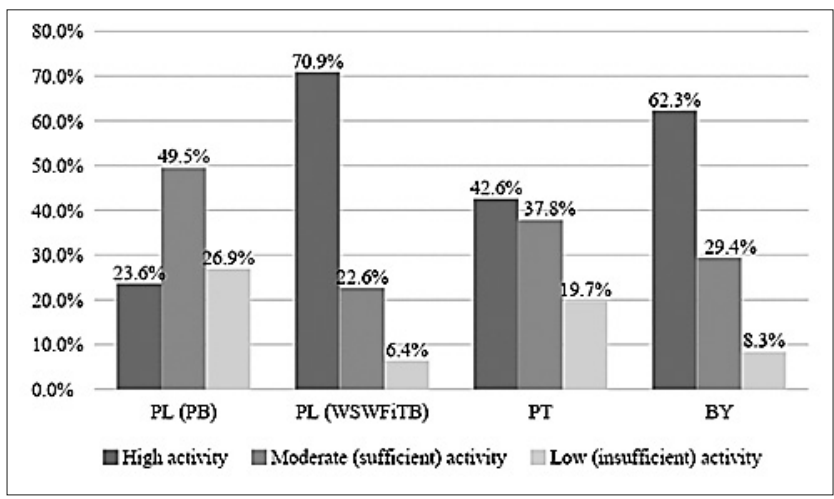

Figure 3. Level of physical activity of students of BUT, WSWFiTB, in Portugal and Belarus $(n=1136)$

Table 3. Time spent on performing specific physical activity with regard to gender (min)

\begin{tabular}{|c|c|c|c|c|c|c|c|c|}
\hline \multicolumn{9}{|l|}{ Men } \\
\hline & \multicolumn{2}{|c|}{$\mathrm{PL}(\mathrm{PB})$} & \multicolumn{2}{|c|}{ PL (WSWFiTB) } & \multicolumn{2}{|c|}{ PT } & \multicolumn{2}{|c|}{ BY } \\
\hline & Me & IQR & $\mathrm{Me}$ & IQR & Me & IQR & Me & IQR \\
\hline Walking [min.] & 140.00 & 225.00 & 300.00 & 275.00 & 280.00 & 415.00 & 360.00 & 420.00 \\
\hline Moderate activity [min.] & 120.00 & 165.00 & 140.00 & 240.00 & 90.00 & 255.00 & 180.00 & 280.00 \\
\hline Vigorous activity [min.] & 45.00 & 180.00 & 240.00 & 240.00 & 180.00 & 240.00 & 240.00 & 300.00 \\
\hline \multicolumn{9}{|l|}{ Women } \\
\hline & \multicolumn{2}{|c|}{$\mathrm{PL}(\mathrm{PB})$} & \multicolumn{2}{|c|}{ PL (WSWFiTB) } & \multicolumn{2}{|c|}{ PT } & \multicolumn{2}{|c|}{ BY } \\
\hline & Me & IQR & $\mathrm{Me}$ & IQR & $\mathrm{Me}$ & $\mathrm{IQR}$ & Me & IQR \\
\hline Walking [min.] & 210.00 & 315.00 & 350.00 & 420.00 & 300.00 & 450.00 & 300.00 & 437.50 \\
\hline Moderate activity [min.] & 75.00 & 180.00 & 135.00 & 240.00 & 60.00 & 210.00 & 120.00 & 210.00 \\
\hline Sitting [min.] & 360.00 & 180.00 & 300.00 & 157.50 & 465.00 & 247.50 & 120.00 & 120.00 \\
\hline
\end{tabular}

Me - median; IQR - interquartile range 
Both among men and women, excluding the information about universities where the respondents studied, the dominant level of activity was at a high level $-58.5 \%$ of the surveyed men and $46.2 \%$ of the surveyed women (Fig. 4 ). Aninsufficient level was recorded among $12.6 \%$ of male students and $16.7 \%$ of female students. The given differences were statistically significant $-\mathrm{p}<0.05$.

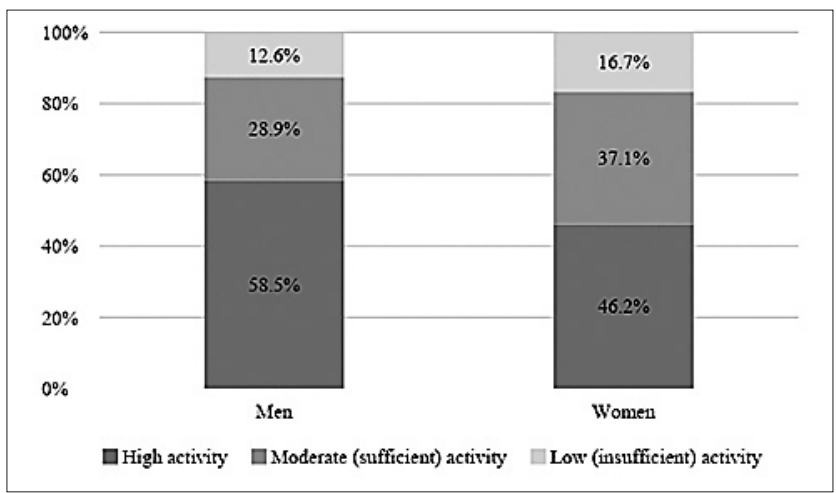

Figure 4. Level of physical activity of students with regard to gender $(n=1,136)$ Pearson Chi-square test value $\times 2=15,765$.png

Without taking into account the gender of the respondents, the highest average value of time spent by students on walking activity was recorded among those studying at WSWFiTB, and the lowest among students of PB - 315 minutes and 205 minutes, respectively $(\mathrm{p}<0.05)$. With regard to walking activity, statistically significant differences were noted between the compared pairs of groups of students PL (PB) - PT, PL (PB) - BY and PL (PB) - PL (WSWFiTB) $(p<0.05)$. Table 4 summarizes the average time spent by the respondents on walking, taking into account statistical significance.

With regard to moderate physical activity, students in Belarus devoted the most time to this type of exercise, followed by students of WSWFiTB, PB and in Portugal (Tab. 5). Taking moderate activity into account, there were statistically significant differences between the compared pairs of groups of the students PT - PL (WSWFiTB), PT BY, PL (PB) - PL (WSWFiTB) and PL (PB) - BY ( $\mathrm{p}<0.05)$.

Intensive activity was most often chosen by respondents of WSWFiTB and in Belarus - 210 minutes and 145 minutes, resectively, while among students in Portugal and BUT this type of exercise was performed sporadically -45 minutes and 60 minutes, respectively. On analyzing the results relating to intensive activity, statistically significant differences ( $\mathrm{p}$ $<0.05$ ) were noted between all the compared pairs of groups of students (Tab. 6).

Persons studying in Portugal spent the most time sitting, followed by students of BUT, WSWFiTB and in Belarus (Tab. 7). With regard to the same activity, statistically significant differences were noticed between all compared pairs of groups of students $(\mathrm{p}<0.05)$.

Men studying at PB, WSWFiTB and in Portugal had a higher average amount of energy expenditure related to walking, compared to women from the same universities.

Table 4. Time spent on walking activity (min)

\begin{tabular}{|c|c|c|c|c|c|c|c|c|}
\hline & \multicolumn{2}{|c|}{ PL (PB) } & \multicolumn{2}{|c|}{ PL (WSWFiTB) } & \multicolumn{2}{|c|}{ PT } & \multicolumn{2}{|c|}{ BY } \\
\hline & $\mathrm{Me}$ & IQR & $\mathrm{Me}$ & IQR & $\mathrm{Me}$ & IQR & $\mathrm{Me}$ & IQR \\
\hline \multirow[t]{2}{*}{ Walking [min.] } & 205.00 & 275.00 & 315.00 & 345.00 & 300.00 & 450.00 & 307.50 & 446.25 \\
\hline & \multicolumn{4}{|c|}{$H=20.780$} & \multicolumn{4}{|c|}{$p=0.000$} \\
\hline Samples & \multicolumn{2}{|c|}{ Statistic } & \multicolumn{2}{|c|}{ SE } & \multicolumn{2}{|c|}{ Standardized statistic } & $\mathrm{P}$ & Adjusted $p$ \\
\hline PL (PB) - PT & \multicolumn{2}{|c|}{-121.037} & \multicolumn{2}{|c|}{28.880} & \multicolumn{2}{|c|}{-4.191} & .000 & .000 \\
\hline PL (PB) - PL (WSWFiTB) & \multicolumn{2}{|c|}{-143.219} & \multicolumn{2}{|c|}{31.515} & \multicolumn{2}{|c|}{-4.544} & .000 & .000 \\
\hline PT - BY & \multicolumn{2}{|c|}{-9.777} & \multicolumn{2}{|c|}{25.893} & \multicolumn{2}{|c|}{-.378} & .706 & 1.000 \\
\hline PT - PL (WSWFiTB) & \multicolumn{2}{|c|}{22.182} & \multicolumn{2}{|c|}{25.487} & \multicolumn{2}{|c|}{.870} & .384 & 1.000 \\
\hline BY - PL (WSWFiTB) & \multicolumn{2}{|c|}{12.405} & \multicolumn{2}{|c|}{28.803} & \multicolumn{2}{|c|}{.431} & .667 & 1.000 \\
\hline
\end{tabular}

Me-median; IQR - interquartile range

Table 5. Time spent performing moderate physical activity (min)

\begin{tabular}{|c|c|c|c|c|c|c|c|c|}
\hline & \multicolumn{2}{|c|}{ PL (PB) } & \multicolumn{2}{|c|}{ PL (WSWFiTB) } & \multicolumn{2}{|c|}{ PT } & \multicolumn{2}{|c|}{ BY } \\
\hline & $\mathrm{Me}$ & IQR & Me & $\mathrm{IQR}$ & $\mathrm{Me}$ & IQR & $\mathrm{Me}$ & IQR \\
\hline \multirow[t]{2}{*}{ Moderate activity [min.] } & 90.00 & 202.50 & 135.00 & 240.00 & 60.00 & 225.00 & 150.00 & 240.00 \\
\hline & \multicolumn{4}{|c|}{$H=17.921$} & \multicolumn{4}{|c|}{$p=0.000$} \\
\hline Samples & \multicolumn{2}{|c|}{ Statistic } & \multicolumn{2}{|c|}{ SE } & \multicolumn{2}{|c|}{ Standardized statistic } & $\mathrm{P}$ & Adjusted $p$ \\
\hline PT - PL (PB) & \multicolumn{2}{|c|}{27.957} & \multicolumn{2}{|c|}{28.640} & \multicolumn{2}{|c|}{.976} & .329 & 1.000 \\
\hline PT - BY & \multicolumn{2}{|c|}{-172.796} & \multicolumn{2}{|c|}{25.679} & \multicolumn{2}{|c|}{-6.729} & .000 & .000 \\
\hline PL (PB) - PL (WSWFiTB) & \multicolumn{2}{|c|}{-131.305} & \multicolumn{2}{|c|}{31.254} & \multicolumn{2}{|c|}{-4.201} & .000 & .000 \\
\hline$P L(P B)-B Y$ & \multicolumn{2}{|c|}{-144.839} & \multicolumn{2}{|c|}{31.580} & \multicolumn{2}{|c|}{-4.586} & .000 & .000 \\
\hline PL (WSWFiTB) - BY & \multicolumn{2}{|c|}{-13.533} & \multicolumn{2}{|c|}{28.565} & \multicolumn{2}{|c|}{-.474} & .636 & 1.000 \\
\hline
\end{tabular}


Table 6. Time spent performing intensive physical activity ( $\mathrm{min}$ )

\begin{tabular}{|c|c|c|c|c|c|c|c|c|}
\hline & \multicolumn{2}{|c|}{ PL (PB) } & \multicolumn{2}{|c|}{ PL (WSWFiTB) } & \multicolumn{2}{|c|}{ PT } & \multicolumn{2}{|c|}{ BY } \\
\hline & $\mathrm{Me}$ & IQR & $\mathrm{Me}$ & IQR & Me & IQR & $\mathrm{Me}$ & IQR \\
\hline \multirow[t]{2}{*}{ Vigorous activity [min.] } & 45.00 & 120.00 & 210.00 & 270.00 & 60.00 & 180.00 & 145.00 & 326.25 \\
\hline & \multicolumn{4}{|c|}{$H=106.980$} & \multicolumn{4}{|c|}{$p=0.000$} \\
\hline Samples & \multicolumn{2}{|c|}{ Statistic } & \multicolumn{2}{|c|}{ SE } & \multicolumn{2}{|c|}{ Standardized statistic } & $P$ & Adjusted $p$ \\
\hline PT - PL (PB) & \multicolumn{2}{|c|}{-86.976} & \multicolumn{2}{|c|}{28.566} & \multicolumn{2}{|c|}{-3.045} & .002 & .014 \\
\hline PT - BY & \multicolumn{2}{|c|}{-316.996} & \multicolumn{2}{|c|}{31.173} & \multicolumn{2}{|c|}{-10.169} & .000 & .000 \\
\hline PL (PB) - PL (WSWFiTB) & \multicolumn{2}{|c|}{-147.976} & \multicolumn{2}{|c|}{25.613} & \multicolumn{2}{|c|}{-5.777} & .000 & .000 \\
\hline$P L(P B)-B Y$ & \multicolumn{2}{|c|}{230.021} & \multicolumn{2}{|c|}{25.211} & \multicolumn{2}{|c|}{9.124} & .000 & .000 \\
\hline PL (WSWFiTB) - BY & \multicolumn{2}{|c|}{82.045} & \multicolumn{2}{|c|}{28.491} & \multicolumn{2}{|c|}{2.880} & .004 & .024 \\
\hline
\end{tabular}

Me-median; IQR - interquartile range

Table 7. Time spent sitting during one working day (min)

\begin{tabular}{|c|c|c|c|c|c|c|c|c|}
\hline & \multicolumn{2}{|c|}{ PL (PB) } & \multicolumn{2}{|c|}{ PL (WSWFiTB) } & \multicolumn{2}{|c|}{ PT } & \multicolumn{2}{|c|}{ BY } \\
\hline & Me & IQR & $\mathrm{Me}$ & IQR & Me & IQR & $\mathrm{Me}$ & IQR \\
\hline \multirow[t]{2}{*}{ Sitting [min.] } & 360.00 & 180.00 & 300.00 & 180.00 & 420.00 & 272.50 & 120.00 & 170.00 \\
\hline & \multicolumn{4}{|c|}{$H=17.332$} & \multicolumn{4}{|c|}{$p=0.000$} \\
\hline Samples & \multicolumn{2}{|c|}{ Statistic } & \multicolumn{2}{|c|}{ SE } & \multicolumn{2}{|c|}{ Standardized statistic } & $P$ & Adjusted $p$ \\
\hline BY - PL (WSWFiTB) & \multicolumn{2}{|c|}{271.112} & \multicolumn{2}{|c|}{28.762} & \multicolumn{2}{|c|}{9.426} & .000 & .000 \\
\hline BY - PT & \multicolumn{2}{|c|}{478.409} & \multicolumn{2}{|c|}{25.839} & \multicolumn{2}{|c|}{18.515} & .000 & .000 \\
\hline PL (WSWFiTB) - PL (PB) & \multicolumn{2}{|c|}{101.217} & \multicolumn{2}{|c|}{31.433} & \multicolumn{2}{|c|}{3.220} & .001 & .008 \\
\hline PL (WSWFiTB) - PT & \multicolumn{2}{|c|}{-207.297} & \multicolumn{2}{|c|}{25.432} & \multicolumn{2}{|c|}{-8.151} & .000 & .000 \\
\hline $\mathrm{PL}(\mathrm{PB})$ - PT & \multicolumn{2}{|c|}{-106.080} & \multicolumn{2}{|c|}{28.782} & \multicolumn{2}{|c|}{-3.686} & .000 & .001 \\
\hline
\end{tabular}

Me-median; IQR - interquartile range

Among men, the median exercise was 462 MET-min/week and $990 \mathrm{MET}-\mathrm{min} /$ week, and $924 \mathrm{MET}-\mathrm{min} /$ week, among women: 693 MET-min/week, 1155 MET-min/week. and $990 \mathrm{MET}$-min/week. The given differences were statistically significant only in the case of persons studying at $\mathrm{PB}(\mathrm{p}<0.05)$.

The lowest average amount of the weekly energy expenditure related to moderate exercise were recorded, both in the group of women and men among Portuguese students - 240 MET$\mathrm{min} /$ week and $360 \mathrm{MET}-\mathrm{min} /$ week The given differences were statistically significant $(\mathrm{p}<0.05)$. Taking into account the average value of the same activity, there were lower results for women than for men at all universities covered by the study (Tab. 8).

Men studying at WSWFiTB, in Portugal and Belarus, had a higher average value of energy expenditure related to vigorous activity, compared to women studying at the same universities (Tab. 8). In the case of people studying at BUT, the same value of the energy consumption median of intensive activity was recorded - $360 \mathrm{MET}-\mathrm{min} /$ week. In the case of respondents in Portugal and Belarus, the differences were statistically significant $(\mathrm{p}<0.05)$.

Women of PB and WSWFiTB obtained higher average results of total energy expenditure compared to men of the same universities. The median of physical exertion was 1,533 MET-min/week and 4,143 MET-min/week, respectively. 1,512 MET-min/week and 3,786 MET-min/week. Within the range of the same activity, statistically significant differences were noted among students in Portugal and Belarus ( $\mathrm{p}<0.05)$. With regard to the above universities, a higher average result of energy consumption was recorded among men compared to women - 3,333 MET-min/week and 4,110 MET-min/week; 2,106 MET-min/week and 3140 MET-min/week (Tab. 8).

Without taking into account the universities where the respondents studied, statistically significant differences were noted between men and women in relation to moderate, intensive and total physical activity $(\mathrm{p}<0.05)$. Women obtained a higher average amount of energy expenditure related to intensive and total activity compared to men. The median of energy consumption was 1,440 MET-min/week, 3,346 MET-min/week and $480 \mathrm{MET}-\mathrm{min} /$ week, 2,486 METmin/week, respectively (Tab. 9). In the case of moderate activity, in both groups of men and women, the same average value of weekly energy consumption was recorded - 480 MET-min/week.

The lowest average values of energy consumption related to walking were recorded among students (men and women in total) of PB - 676.50 MET/week, followed by those studying in Portugal - 990 MET-min/week, in Belarus - 1014.75 MET$\mathrm{min} /$ week, and of WSWFiTB - 1039.5 MET-min/week. Table 10 shows the energy expenditure of the respondents taking into account the university and statistical significance. In the case of walking activity, there were statistically significant differences between the compared pairs of student groups PL (PB) - PT, PL (PB) - BY and PL (PB) - PL (WSWFiTB) $(\mathrm{p}<0.05)$.

Without taking into account gender of the respondents, persons studying in Belarus were characterized by the highest amount of average energy expenditure associated 
Table 8. Differences in physical activity of students of BUT, WSWFiTB, in Portugal and Belarus, with regard to gender and statistical significance

\begin{tabular}{|c|c|c|c|c|c|c|c|c|}
\hline \multicolumn{9}{|l|}{ Men } \\
\hline \multirow{2}{*}{ MET-min/week } & \multicolumn{2}{|c|}{ PL (PB) } & \multicolumn{2}{|c|}{ PL (WSWFiTB) } & \multicolumn{2}{|c|}{ PT } & \multicolumn{2}{|c|}{ BY } \\
\hline & Me & IQR & $\mathrm{Me}$ & IQR & Me & IQR & Me & IQR \\
\hline Walking & 462.00 & 742.50 & 990.00 & 907.50 & 924.00 & 1369.50 & 1188.00 & 1386.00 \\
\hline Moderate activity & 480.00 & 660.00 & 560.00 & 960.00 & 360.00 & 1020.00 & 720.00 & 1120.00 \\
\hline Vigorous activity & 360.00 & 1440.00 & 1920.00 & 1920.00 & 1440.00 & 1920.00 & 1920.00 & 2400.00 \\
\hline Total physical activity & 1512.00 & 2085.00 & 3786.00 & 3666.00 & 3333.00 & 3361.50 & 4110.00 & 3682.00 \\
\hline \multicolumn{9}{|l|}{ Women } \\
\hline \multirow{2}{*}{ MET (min/week) } & \multicolumn{2}{|c|}{ PL (PB) } & \multicolumn{2}{|c|}{ PL (WSWFiTB) } & \multicolumn{2}{|c|}{ PT } & \multicolumn{2}{|c|}{ BY } \\
\hline & $\mathrm{Me}$ & IQR & $\mathrm{Me}$ & IQR & $\mathrm{Me}$ & IQR & $\mathrm{Me}$ & IQR \\
\hline Walking & 693.00 & 1039.50 & 1155.00 & 1386.00 & 990.00 & 1485.00 & 990.00 & 1443.75 \\
\hline Moderate activity & 300.00 & 720.00 & 540.00 & 960.00 & 240.00 & 840.00 & 480.00 & 840.00 \\
\hline Vigorous activity & 360.00 & 720.00 & 1440.00 & 2310.00 & 480.00 & 1200.00 & 960.00 & 1920.00 \\
\hline Total physical activity & 1533.00 & 1456.50 & 4143.50 & 3495.75 & 2106.00 & 3001.50 & 3140.00 & 2744.50 \\
\hline \multirow{2}{*}{ MET (min/week) } & \multicolumn{2}{|c|}{ PL (PB) } & \multicolumn{2}{|c|}{ PL (WSWFiTB) } & \multicolumn{2}{|c|}{ PT } & \multicolumn{2}{|c|}{ BY } \\
\hline & z & $\mathrm{p}$ & z & $\mathrm{p}$ & z & $\mathrm{p}$ & $\mathrm{p}$ & z \\
\hline Walking & -2.196 & 0.028 & -1.051 & 0.293 & -0.159 & 0.873 & -0.800 & 0.423 \\
\hline Moderate activity & -1.874 & 0.061 & -0.458 & 0.647 & -2.129 & 0.033 & -1.509 & 0.131 \\
\hline Vigorous activity & -1.385 & 0.166 & -1.798 & 0.072 & -5.866 & 0.000 & -2.807 & 0.005 \\
\hline Total physical activity & -0.047 & 0.963 & -0.112 & 0.911 & -3.357 & 0.001 & -2.305 & 0.021 \\
\hline
\end{tabular}

Me-median; IQR - interquartile range

Table 9. Differences in physical activity of women and men

\begin{tabular}{|c|c|c|c|c|c|c|}
\hline \multirow{2}{*}{ MET-min/week } & \multicolumn{2}{|c|}{ Women } & \multicolumn{2}{|c|}{ Men } & \multicolumn{2}{|c|}{ Statistic } \\
\hline & $\mathrm{Me}$ & IQR & Me & IQR & Z & $\mathrm{p}$ \\
\hline Walking & 792.0000 & 1188.00 & 924.0000 & 1353.00 & -1.412 & 0.158 \\
\hline Moderate activity & 480.0000 & 1040.00 & 480.0000 & 960.00 & -3.493 & 0.000 \\
\hline Vigorous activity & 1440.0000 & 2400.00 & 480.0000 & 1440.00 & -7.875 & 0.000 \\
\hline Total activity & 3346.5000 & 3322.75 & 2486.0000 & 3133.95 & -5.058 & 0.000 \\
\hline
\end{tabular}

Me-median; IQR - interquartile range

Table 10. Differences in physical activity related to walking, not including gender

\begin{tabular}{|c|c|c|c|c|c|c|c|c|}
\hline \multirow{2}{*}{ MET-min/week } & \multicolumn{2}{|c|}{$\mathrm{PL}(\mathrm{PB})$} & \multicolumn{2}{|c|}{ PL (WSWFiTB) } & \multicolumn{2}{|c|}{ PT } & \multicolumn{2}{|c|}{ BY } \\
\hline & Me & IQR & $\mathrm{Me}$ & IQR & Me & IQR & Me & IQR \\
\hline \multirow[t]{2}{*}{ Walking } & 676.50 & 907.50 & 1039.50 & 1138.50 & 990.00 & 1485.00 & 1014.75 & 1472.63 \\
\hline & \multicolumn{4}{|c|}{$H=24.784$} & \multicolumn{4}{|c|}{$p=0.000$} \\
\hline Samples & \multicolumn{2}{|c|}{ Statistic } & \multicolumn{2}{|c|}{ SE } & \multicolumn{2}{|c|}{ Standardized statistic } & $\mathrm{P}$ & Adjusted $\mathrm{p}$ \\
\hline$P L(P B)-P T$ & \multicolumn{2}{|c|}{-121.037} & \multicolumn{2}{|c|}{28.880} & \multicolumn{2}{|c|}{-4.191} & .000 & .000 \\
\hline$P L(P B)-B Y$ & \multicolumn{2}{|c|}{-130.814} & \multicolumn{2}{|c|}{31.844} & \multicolumn{2}{|c|}{-4.108} & .000 & .000 \\
\hline PL (PB) - PL (WSWFiTB) & \multicolumn{2}{|c|}{-143.219} & \multicolumn{2}{|c|}{31.515} & \multicolumn{2}{|c|}{-4.544} & .000 & .000 \\
\hline PT - BY & \multicolumn{2}{|c|}{-9.777} & \multicolumn{2}{|c|}{25.893} & \multicolumn{2}{|c|}{-.378} & .706 & 1.000 \\
\hline PT - PL (WSWFiTB) & \multicolumn{2}{|c|}{22.182} & \multicolumn{2}{|c|}{25.487} & \multicolumn{2}{|c|}{.870} & .384 & 1.000 \\
\hline BY - PL (WSWFiTB) & \multicolumn{2}{|c|}{12.405} & \multicolumn{2}{|c|}{28.803} & \multicolumn{2}{|c|}{.431} & .667 & 1.000 \\
\hline
\end{tabular}

Me - median; IQR - interquartile range

with moderate activity, compared to those studying at WSWFiTB, PB and in Portugal (Tab. 11). The median of moderate-intensity exercise was $600 \mathrm{MET}-\mathrm{min} /$ week. In the group of Belarusian students - $540 \mathrm{MET}$-min/week. among students of WSWFiTB - $360 \mathrm{MET}$-min/week in the group of BUT students, and 240 MET-min/week among Portuguese students. With regard to moderate activity, there were statistically significant differences between the compared pairs of student groups PT - PL (WSWFiTB), PT - BY, PL (PB) - PL (WSWFiTB) and PL (PB) - BY ( $\mathrm{p}<0.05)$.

Without taking into account gender of the respondents, those studying at WSWFiTB were characterized by the highest average amount of energy consumption related to intensive activity - $1680 \mathrm{MET}-\mathrm{min} /$ week. The lowest amount of energy was recorded among BUT students, with the median of energy expenditure at $360 \mathrm{MET}$-min/week 
Table 11. Moderate physical activity of students (men and women jointly) of BUT, WSWFiTB, in Portugal and Belarus

\begin{tabular}{|c|c|c|c|c|c|c|c|c|}
\hline \multirow{2}{*}{ MET-min/week } & \multicolumn{2}{|c|}{$\mathrm{PL}(\mathrm{PB})$} & \multicolumn{2}{|c|}{ PL (WSWFiTB) } & \multicolumn{2}{|c|}{ PT } & \multicolumn{2}{|c|}{ BY } \\
\hline & Me & IQR & Me & IQR & Me & IQR & $\mathrm{Me}$ & IQR \\
\hline \multirow[t]{2}{*}{ Moderate activity } & 360.00 & 810.00 & 540.00 & 960.00 & 240.00 & 900.00 & 600.00 & 960.00 \\
\hline & \multicolumn{4}{|c|}{$H=67.599$} & \multicolumn{4}{|c|}{$\mathrm{p}=\mathbf{0 . 0 0 0}$} \\
\hline Samples & \multicolumn{2}{|c|}{ Statistic } & \multicolumn{2}{|c|}{ SE } & \multicolumn{2}{|c|}{ Standardized statistic } & $\mathrm{P}$ & Adjusted $\mathrm{p}$ \\
\hline PT - PL (PB) & \multicolumn{2}{|c|}{27.957} & \multicolumn{2}{|c|}{28.640} & \multicolumn{2}{|c|}{976} & .329 & 1.000 \\
\hline PT - PL (WSWFiTB) & \multicolumn{2}{|c|}{159.262} & \multicolumn{2}{|c|}{25.276} & \multicolumn{2}{|c|}{6.301} & .000 & .000 \\
\hline PT - BY & \multicolumn{2}{|c|}{-172.796} & \multicolumn{2}{|c|}{25.679} & \multicolumn{2}{|c|}{-6.729} & .000 & .000 \\
\hline PL (PB) - PL (WSWFiTB) & \multicolumn{2}{|c|}{-131.305} & \multicolumn{2}{|c|}{31.254} & \multicolumn{2}{|c|}{-4.201} & .000 & .000 \\
\hline$P L(P B)-B Y$ & \multicolumn{2}{|c|}{-144.839} & \multicolumn{2}{|c|}{31.580} & \multicolumn{2}{|c|}{-4.586} & .000 & .000 \\
\hline PL (WSWFiTB) - BY & \multicolumn{2}{|c|}{-13.533} & \multicolumn{2}{|c|}{28.565} & \multicolumn{2}{|c|}{-.474} & 636 & 1.000 \\
\hline
\end{tabular}

Me - median; IQR - interquartile range

Table 12. Differences in intensive physical activity of students of BUT, WSWFiTB, in Portugal and Belarus, not including gender

\begin{tabular}{|c|c|c|c|c|c|c|c|c|}
\hline \multirow{2}{*}{ MET-min/week } & \multicolumn{2}{|c|}{ PL (PB) } & \multicolumn{2}{|c|}{ PL (WSWFiTB) } & \multicolumn{2}{|c|}{ PT } & \multicolumn{2}{|c|}{ BY } \\
\hline & Me & IQR & $\mathrm{Me}$ & IQR & Me & IQR & Me & IQR \\
\hline \multirow[t]{2}{*}{ Vigorous activity } & 360.00 & 960.00 & 1680.00 & 2160.00 & 480.00 & 1440.00 & 1160.00 & 2610.00 \\
\hline & \multicolumn{4}{|c|}{$H=142.457$} & \multicolumn{4}{|c|}{$p=0.000$} \\
\hline Samples & \multicolumn{2}{|c|}{ Statistic } & \multicolumn{2}{|c|}{ SE } & \multicolumn{2}{|c|}{ Standardized statistic } & $P$ & Adjusted $p$ \\
\hline PL (PB) - PT & \multicolumn{2}{|c|}{-86.976} & \multicolumn{2}{|c|}{28.566} & \multicolumn{2}{|c|}{-3.045} & .002 & .014 \\
\hline $\mathrm{PL}(\mathrm{PB})$ - BY & \multicolumn{2}{|c|}{-234.951} & \multicolumn{2}{|c|}{31.499} & \multicolumn{2}{|c|}{-7.459} & .000 & .000 \\
\hline PL (PB) - PL (WSWFiTB) & \multicolumn{2}{|c|}{-316.996} & \multicolumn{2}{|c|}{31.173} & \multicolumn{2}{|c|}{-10.169} & .000 & .000 \\
\hline PT - BY & \multicolumn{2}{|c|}{-147.976} & \multicolumn{2}{|c|}{25.613} & \multicolumn{2}{|c|}{-5.777} & .000 & .000 \\
\hline PT - PL (WSWFiTB) & \multicolumn{2}{|c|}{230.021} & \multicolumn{2}{|c|}{25.211} & \multicolumn{2}{|c|}{9.124} & .000 & .000 \\
\hline BY - PL (WSWFiTB) & \multicolumn{2}{|c|}{82.045} & \multicolumn{2}{|c|}{28.491} & \multicolumn{2}{|c|}{2.880} & .004 & .024 \\
\hline
\end{tabular}

Me-median; IQR - interquartile range

(Tab. 12). The given differences were statistically significant $(\mathrm{p}<0.05)$.

Within the range of total activity, the highest average amount of energy expenditure was recorded in the group of students (men and women together) of WSWFiTB, followed by students of Belarus, Portugal and BUT (Tab. 13). The median total physical effort was 3,972 MET-min/week, 3,523 MET-min/week, and 2,346 MET-min/week, respectively, and 1524 MET-min / week. With regard to total effort, there were statistically significant differences between the compared pairs of student groups, excluding the pair of student groups BY - PL (WSWFiTB) ( $\mathrm{p}<0.05)$.

The prevailing level of activity regarding persons with BMI below $25 \mathrm{~kg} / \mathrm{m}^{2}$ (underweight/normal body weight), students with BMI between $25-29.99 \mathrm{~kg} / \mathrm{m}^{2}$ (overweight) and respondents with BMI of at least $30 \mathrm{~kg} / \mathrm{m}^{2}$ (obesity), was high $-50.6 \%, 47.9 \%$ and $65 \%$, respectively (Fig. 5). An insufficient level of activity was characterized by $14.9 \%$ underweight/ normal weight, $18.8 \%$ overweight and $5 \%$ obese respondents.

The highest average amount of energy expenditure in the group of persons with underweight/normal body weight was recorded in the case of walking activity - 990 MET$\mathrm{min} /$ week, followed by intensive activity - $800 \mathrm{MET}-\mathrm{min} /$ week, and moderate activity - 480 MET-min/week. With regard to overweight and obese people, the highest average amount of energy expenditure was recorded in the case of intensive activity (Tab. 14). Taking into account the abovementioned groups, the mean value of intensive exercise was 960 MET-min/week. Students with a minimum BMI of

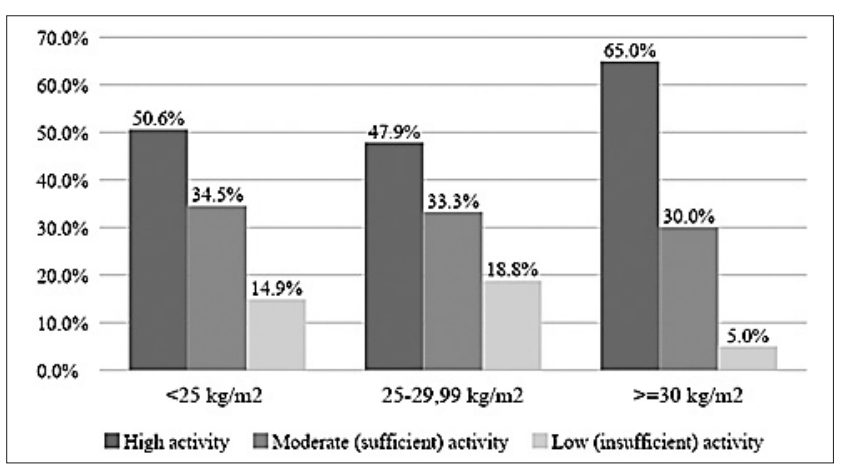

Figure 5. Activity level of respondents taking BMI values into account $(n=1136)$

$30 \mathrm{~kg} / \mathrm{m}^{2}$ obtained the highest average result of total energy expenditure, compared to those with a BMI of $25-29.99 \mathrm{~kg} / \mathrm{m}^{2}$ and less than $25 \mathrm{~kg} / \mathrm{m}^{2}$. The median of energy consumption was 3,742.25 MET-min/week, 2,726.25 MET-min/week and 2726.25 MET-min/week, respectively. The given differences were not statistically significant ( $p>0.05)$.

\section{DISCUSSION}

A study on the assessment of the level of physical activity among 692 Colombian students was carried out by Diaz Muñoz et al. [17], in which students of health sciences took part. The average age of the respondents was 18 years. The results obtained indicated that the dominant level of activity 
Table 13. Differences in total physical activity of students (men and women together) of BUT, WSWFiTB, in Portugal and Belarus

\begin{tabular}{|c|c|c|c|c|c|c|c|c|}
\hline \multirow{2}{*}{ MET-min/week } & \multicolumn{2}{|c|}{$\mathrm{PL}(\mathrm{PB})$} & \multicolumn{2}{|c|}{ PL (WSWFiTB) } & \multicolumn{2}{|l|}{ PT } & \multicolumn{2}{|c|}{ BY } \\
\hline & $\mathrm{Me}$ & IQR & $\mathrm{Me}$ & IQR & Me & $\mathrm{IQR}$ & Me & IQR \\
\hline \multirow[t]{2}{*}{ Total activity } & 1524.00 & 1811.25 & 3972.00 & 3625.75 & 2346.00 & 2973.00 & 3523.00 & 2981.75 \\
\hline & \multicolumn{4}{|c|}{$H=143.586$} & \multicolumn{4}{|c|}{$p=0.000$} \\
\hline Samples & Stat & & SE & & Standardized & istic & $\mathrm{P}$ & Adjusted $\mathrm{p}$ \\
\hline$P L(P B)-P T$ & -120 & & 28.943 & & -4.16 & & .000 & .000 \\
\hline PL (PB) - PL (WSWFiTB) & -325 & & 31.584 & & -10.3 & & .000 & .000 \\
\hline PT - BY & -156 & & 25.950 & & -6.04 & & .000 & .000 \\
\hline PT - PL (WSWFiTB) & 205 & & 25.544 & & 8.03 & & .000 & .000 \\
\hline BY - PL (WSWFiTB) & 48. & & 28.867 & & 1.67 & & .094 & .564 \\
\hline
\end{tabular}

Me-median; IQR - interquartile range

Table 14. Energy expenditure of the respondents with regard to BMI

\begin{tabular}{|c|c|c|c|c|c|c|}
\hline \multirow{2}{*}{ MET min/week } & \multicolumn{2}{|c|}{$<25$} & \multicolumn{2}{|c|}{$25-29,99$} & \multicolumn{2}{|c|}{$>=30$} \\
\hline & Me & IQR & Me & IQR & Me & $\mathrm{IQR}$ \\
\hline Walking & 990.00 & 1386.00 & 693.00 & 924.00 & 841.50 & 1658.25 \\
\hline Moderate activity & 480.00 & 960.00 & 480.00 & 960.00 & 240.00 & 900.00 \\
\hline Vigorous activity & 800.00 & 1920.00 & 960.00 & 2400.00 & 960.00 & 2580.00 \\
\hline Total activity & 2826.00 & 3309.75 & 2726.25 & 3306.25 & 3742.25 & 3195.63 \\
\hline
\end{tabular}

Me-median; IQR - interquartile range

among Colombian students was insufficient (low), found in $49 \%$ of the respondents. The level of physical activity was also assessed by Walentukiewicz et al. [18]. The study included 74 first-year female nursing students. Insufficient (low) level of activity was noted in $58 \%$ of the respondents, and sufficient (moderate) in $42 \%$.

On the other hand, research showed that the dominant level of activity among Portuguese and Belarusian students was high level, and among PB students was sufficient (moderate). WSWFiTB students who were studying professional or coaching programmes were also characterized by a high level of physical activity. Additionally, in relation to total physical activity, this research showed a higher average amount of energy consumption of students of BUT, WSWFiTB, in Portugal and Belarus, than of students in Colombia $-\mathrm{Me}=$ $1188 \mathrm{MET}-\mathrm{min} /$ week.

Tsos et al. [19], in turn, in their research using the short version of the IPAQ Questionnaire, noted even more people characterized by an insufficient (low) level of activity $-73.4 \%$ of respondents. The study group consisted of 308 women studying at the Lesya Ukrainka East European National University in Lutsk, Ukraine. Popovych et al. [20] in a study involving 333 students of the State Medical University in Ternopil, Ukraine, reported an insufficient (low) level in $80.2 \%$ of the respondents. The occasionally occurring activity level in this group was high in $3.9 \%$ of women.

Based on the performed study, it was found that the dominant level of activity among women studying at WSWFiTB and in Belarus was at high level $-70.9 \%$ and $60.5 \%$ of the respondents, while among the female students of BUT and in Portugal, the dominant level was sufficient, or moderate $-53.7 \%$ and $41 \%$ of respondents.

Also, research conducted by Junger et al. [21] showed that the dominant level of activity among 2,237 students $(1,169$ women and 1,068 men) was high, amounting to $49.7 \%$ in the group of people studying humanities, 50.9\% among medical students and $50.1 \%$ in the group of students of technical faculties. Moreover, in the group of men, a high level of physical activity dominated, amounting to $56.2 \%$ of the surveyed students of humanities, $60.7 \%$ of medical faculties and $56.2 \%$ of technical faculties. In the case of women, as well as the female students of BUT and in Portugal, the dominant level was the sufficient (moderate) level found in $47.2 \%$ of respondents studying the humanities, $46.9 \%$ among medical female students and $49.1 \%$ in the group of technical students.

Papathanasiou et al. [22] in a study carried out on a group of 218 people (113 men and 105 women) studying at the Technological Educational Institute in Athens (TEI-A) and 175 people (77 men and 98 women) studying at the University of Ioannina (Greece, analyzed the physical activity undertaken by students. With regard to the first day of the study, among the surveyed women, the highest average amount of energy consumption was recorded in the case of exercise related to walking. The median of energy expenditure was $396 \mathrm{MET}$-min/week for female students from TEI-A and $330 \mathrm{MET}-\mathrm{min} /$ week for female students from Ioannina. As regards men, moderate exercise was the least frequently chosen form of activity, the mean value for this activity was $180 \mathrm{MET}-\mathrm{min} /$ week for men studying at TEI-A and $160 \mathrm{MET}-$ min/week for men studying at Ioannina. Moreover, men studying TEI-A and Ioannina had a statistically significantly higher mean amount of total energy expenditure compared to women from the same universities $(\mathrm{p}<0.05)$.

The current study showed that women studying at BUT, in Portugal and Belarus, similarly to female students in TEI-A and Ioannina, obtained the highest average amount of energy consumption in relation to walking activity. Analysis of the results of the study also showed that men studying at WSWFiTB, in Portugal and Belarus, obtained the lowest average amount of energy expenditure in relation 
to moderate activity. As in the case of respondents from TEI-A and Ioannina, men studying in Portugal and Belarus were characterized by a higher amount of average energy expenditure related to total activity, compared to women from the same universities.

Similar studies were conducted in Poland in a group of 953 students of the Academy of Physical Education in Wrocław (AWF) and 200 students of the University of Wrocław (UW), Starościak, Guła-Kubiszewska, Kałwa and Dębsk [23]. In the group of students (women and men jointly) from AWF and UW, the level of activity was high $-86.6 \%$ and $58 \%$ of the respondents, respectively. Moreover, among the women, the highest average amount of energy expenditure was recorded for vigorous activity, followed by walking and moderate activity. The median of energy consumption was $2,807.62$ MET-min/week, 1,533.18 MET-min/week, and 1,084.23 MET-min/week, respectively.

The results of the current study, referring to the recorded levels of activity of students of WSWFiTB, in Portugal and Belarus, are consistent with the results obtained by Starościak et al. The high level of physical activity - 70.9\%, $42.6 \%$ and $62.3 \%$ of the respondents, the same as in the case of female students of AWF and UW women studying at BUT, WSWFiTB, in Portugal and Belarus, who obtained the highest average amount of energy consumption in relation to intensive activity, followed by walking at a moderate level.

In turn, Stepień et al. [24] undertook the assessment of level of physical activity among 544 students of the State University of Pope John Paul II in Biała Podlaska (PSW, Poland. The most frequently observed level of student activity was the sufficient (moderate) level, recorded in $66 \%$ of IT students, $65.6 \%$ of public health students, $53.3 \%$ of nursing students, $52.9 \%$ of emergency medical students and $52 \%$ of tourism and recreation students. The students of BUT were also characterized by a sufficient (moderate) level of activity $-49.5 \%$ of the respondents.

In the study conducted by Łuczak et al. [25], the dominant level of activity among 249 female students of the College of Engineering and Health was at the sufficient (moderate) level, found in $52.21 \%$ of the respondents. A high level was characteristic of $30.12 \%$ of the respondents, and the insufficient (low) level $-17.67 \%$ of the respondents. In the group of women studied by Łuczak et al., the highest result for the average amount of energy expenditure involving exercise of walking was 1,463 MET-min/week, followed by intensive activity - $540 \mathrm{MET}-\mathrm{min} / \mathrm{week}$, and moderate activity - 521 MET-min/week.

The result, which was similar to that obtained by Łuczak et al., determining the level of physical activity was presented by Kościuczuk et al. [26] on the basis of a study carried out among 200 students of the Medical University of Białystok. The dominant level of activity was at the moderate (sufficient) level, found in $67 \%$ of the respondents, and the highest amount of average energy expenditure was recorded in relation to walking activity - 1,160.6 MAT-min/week.

The result of the current study are similar to those reported by Łuczak et al. and Kościuczuk et al. among the women studying at WSWFiTB and in Portugal. In the group of female students in Portugal, the level of activity was sufficient (moderate), found in $41 \%$ of the respondents, while the least number of women was characterized by an insufficient (low) level of physical activity $-20.1 \%$. Women studying at WSWFiTB obtained the highest average result of energy consumption in relation to the exercise of walking, followed by intensive and moderate activity.

Popovych et al. in their study also assessed the level of physical activity depending on the BMI value of the surveyed women [20]. The highest average amount of total energy expenditure was recorded in the group of female students with normal body weight - 5357.6 MET-min/week, followed by overweight people-5,399.6 MET-min/week. On the other hand, in the group of students in this study, the highest average amount of energy expenditure was recorded among people with obesity - 3,742.25 MET-min/week, and then among those with underweight or normal body weight $2826 \mathrm{MET}$-min/week).

Bergier et al. [27] conducted research in a group of 450 students of the State University of Pope John Paul II in Biała Podlaska (PSW). The authors found that men spent more time sitting in one working day compared to women - 347 min and $312 \mathrm{~min}$, respectively. Analysis of the results of this study also showed that men studying at BUT and in Belarus spent more time sitting during one working day, compared to women studying at the same universities.

Dugas et al. [28] compared the time spent on performing specific physical activities by 2,500 people from the African communiiesy studying in Ghana, South Africa, Seychelles, Jamaica, and Chicago in the USA. Women from all the universities listed, and men studying in South Africa, Seychelles, Jamaica, and Chicago, spent the most time sitting. Based on this study, similar results were reported for men and women studying at PB and in Portugal.

Matei and Ginsborg [29] also assessed the time spent by UK university graduates performing specific physical exertion. The highest mean amount of time noted by the authors was activity related to walking - $416 \mathrm{~min}$. Similar results were recorded in the current study, in which specifically students (women and men jointly) studying at BUT, WSWFiTB, in Portugal and Belarus, spent most of their time performing activity related to walking.

The main limitation of te current study is the possible over-reporting and under-estimating of the duration and intensity of physical activity undertaken by students. Because the respondents themselves provided data on their height and body weight, values important for the analyzes and conclusions relating to BMI, this rendered them unreliable. Nevertheless, the results of research on the level of physical activity can be used to promote a healthy lifestyle, active rest, and to ensure an appropriate educational programe at universities.

\section{CONCLUSIONS}

Men studying at the University of Physical Education and Tourism in Białystok (WSWFiTB), in Portugal and Belarus, were characterized by a high level of physical activity, while students of Białystok University of Technology (PB) were characterized by a sufficient level of physical activity.

Among women of WSWFiTB and in Belarus, a high level of physical activity prevailed, while among female students from Portugal and BUT the level was sufficient.

Students in Portugal spent more time sitting during one working day than students of BUT, WSWFiTB, and in Belarus. 
Men, compared to women, were characterized by a higher average amount of energy consumption related to total activity and intensive exercise.

The lowest mean values of total activity were observed for both women and men studying at BUT.

Students in Belarus obtained the highest average amount of energy expenditure related to moderate and intensive activity, compared to students at BUT, WSWFiTB, and in Portugal.

A high level of activity dominated both in the group of underweight/normal body weight, as well as overweight and obese persons.

\section{REFERENCES}

1. Vuori I. World Health Organization and Physical Activity. Prog Prev Med. 2018; 3(1): e0012. doi: 10.1097/pp9.0000000000000012

2. WHO guidelines on physical activity and sedentary behaviour: Web Annex. Evidence profiles. Geneva, World Health Organization, 2020.

3. Syed Ali SK. The important of physical activities in our life. Int Phys Med Rehab J. 2018; 3(4): 308-310. doi: 10.15406/ipmrj.2018.03.00121

4. Global action plan on physical activity 2018-2030: more active people for a healthier world. Geneva, World Health Organization, 2018.

5. Aune D, Schlesinger S, Leitzmann M, et al. Physical activity and the risk of heart failure: a systematic review and dose-response meta-analysis of prospective studies. Eur J Epidemiol. 2021; 36(4):367-381. doi: 10.1007/ s10654-020-00693-6

6. Kruk J. Physical activity and health. Asian Pac J Cancer Prev. 2009; 10(5): 721-728.

7. Biernat E, Stupnicki R, Gajewski AK. International Physical Activity Questionnaire (IPAQ) - Polish version. Wych Fiz I Sport. 2007; 51(1): 47-54.

8. Byrne N, Hills A, Hunter G, et al. Metabolic equivalent: one size does not fit all. J Appl Physiol, 2005; 99(3): 1112-1119. doi: 10.1152/ japplphysiol.00023.2004

9. Franklin B, Brinks J, Berra K, et al. Using Metabolic Equivalents in Clinical Practice. Am J Cardiol. 2018; 121(3): 382-387. doi: 10.1016/j. amjcard.2017.10.033

10. Holtermann A, Stamatakis E. Do all daily metabolic equivalent task units (METs) bring the same Health benefits. Br J Sports Med. 2019; 53(16): 991-992. doi: 10.1136/bjsports-2017-098693

11. Mendes MA, da Silva I, Ramires V, et al. Metabolic equivalent of task (METs) thresholds as an indicator of physical activity intensity. PLoS One. 2018; 13(7): e 0200701. doi: 10.1371/journal.pone.0200701

12. Craig C, Marshall A, Sjöström M, et al. International physical activity questionnaire: 12-country reliability and validity. Med Sci Sports Exerc. 2003; 35(8): 1381-1395. doi: 10.1249/01.MSS.0000078924.61453.FB

13. Gajewski A, Biernat E. Zastosowanie Międzynarodowego Kwestionariusza Aktywności Fizycznej (IPAQ) - za i przeciw, czyli kilka rozważań metodycznych i ich konsekwencje. In: Buśko K, Charzewska J, Kaczanowski K, editors. Współczesne metody badań aktywności, sprawności i wydolności fizycznej człowieka. Warszawa: Wyd. AWF; 2010. p. 20-37.
14. Bergier J. About physical activity with the application of the polish version of the international physical activity questionnaire (ipaq) participation in discussion. Human and Health. 2013; 7(1): 91-98.

15. Physical status: the use and interpretation of anthropometry. Report of a WHO Expert Committee. World Health Organ Tech Rep Ser. 1995; 854: 1-452.

16. Nuttall F. Body Mass Index. Obesity, BMI, and Health: A Critical Review. Nutr Today. 2015; 50(3): 117-128. doi: 10.1097/NT.0000000000000092

17. Díaz-Muñoz GA, Pérez Hoyos AK, Cala Liberato DP, et al. Difference in levels of physical activity, sedentary lifestyle, and eating habits among university students from different health programs at a private university in Bogotá, Colombia. Revista Española De Nutrición Humana Y Dietética, 2021;25(1): 8-17. https://doi.org/10.14306/renhyd.25.1.1007

18. Walentukiewicz A, Łysak A, Wilk B. Health behavior of nursing students. Nursing Problems/Problemy Pielęgniarstwa. 2013; 21(4): $484-488$.

19. Tsos A, Kasarda O, Pantik V, Female students at higher educational Institutions in Ukraine and their level of physical activity. Health Problems of Civilization. 2017; 11(3): 158-162. https://doi.org/10.5114/ hpc.2017.70004

20. Popovych D, Bergier J, Korda M, et al. Evaluation of physical activity, body mass index and self-assessment of physical fitness in female students and pupils of Ternopil, Western Ukraine. Health Problems of Civilization. 2017; 11(3): 163-172. https://doi.org/10.5114/ hpc.2017.70006

21. Junger J, Niźnikowska E, Bergier B, et al. A field of study as a factor determining physical activity, BMI, indicator and self-assessment of physical activity of students in the visegrad countries. Health Problems of Civilization 2016; 10(4): 14-25. https://doi.org/10.5114/ hpc.2016.63567

22. Papathanasiou G, Georgoudis G, Papandreou M, et al. Reliability measures of the short International Physical Activity Questionnaire (IPAQ) in Greek young adults. Hellenic J Cardiol. 2009; 50(4): 283-294.

23. Starościak W, Guła-Kubiszewska H, Kałwa M, et al. Physical activity of students in the era of globalization. Journal of Education. Health and Sport. 2016; 6(13): 96-114. doi: 10.5281/zenodo.233002

24. Stepień E, Bergier B, Bergier J, et al. The relationship between the level of physical activity of students and the direction of their studies. Med Sport. 2014; 3(4): 189-198. doi: 10.5604/1232406X.1122191

25. Łuczak J, Wolska A, Michalik J. Determinants of physical activity students of the College of Engineering and Health. Fizjoter Pol. 2019; 19(2): 158-167.

26. Kościuczuk J, Krajewska-Kułak E, Okurowska-Zawada B. Aktywność fizyczna studentów fizjoterapii i dietetyki. Med Og Nauk Zdr. 2016; 22(1): 51-58. doi: https://doi.org/10.5604/20834543.1198724

27. Bergier B, Stępień E, Niźnikowska E, et al. Aktywność fizyczna kobiet i mężczyzn studiujących w Państwowej Szkole Wyższej w Białej Podlaskiej. Med Og Nauk Zdr. 2014; 20(2): 166-170. doi: $10.5604 / 20834543.1112232$

28. Dugas L, Bovet P, Forrester T, et al. Comparisons of intensityduration patterns of physical activity in the USA, Jamaica and 3 African countries. BMC Public Health. 2014; 14: 882. doi: https://doi. org/10.1186/1471-2458-14-882

29. Matei R, Ginsborg J. Physical Activity, Sedentary Behavior, Anxiety, and Pain Among Musicians in the United Kingdom. Front Psychol. 2020; 11: 560026. doi: 10.3389/fpsyg.2020.560026 